BMJ Surgery, Interventions, \& Health Technologies

\section{Joint effort: a call for standardization in total joint arthroplasty data reporting}

To cite: Liebeskind AY, Nieuwenhuijse M, Hyde JH, et al. Joint effort: a call for standardization in total joint arthroplasty data reporting. BMJ Surg Interv Health Technologies 2021;3:e000079. doi:10.1136/ bmjsit-2021-000079

Accepted 10 July 2021

\section{Check for updates}

(c) Author(s) (or their employer(s)) 2021. Re-use permitted under CC BY-NC. No commercial re-use. See rights and permissions. Published by BMJ.

${ }^{1}$ Department of Health Policy and Research, Weill Cornell Medical College, New York, New York, USA

${ }^{2}$ Orthopaedic Surgery, Maastricht University Medical Center+, Maastricht, The Netherlands

${ }^{3}$ Orthopaedic Surgery, Leiden University Medical Center, Leiden, The Netherlands ${ }^{4}$ Department of Internal Medicine, The University of Tennessee at Chattanooga, Chattanooga, Tennessee, USA ${ }^{5}$ Sport Medicine Institute, Hospital for Special Surgery, New York, New York, USA ${ }^{6}$ Departement of Orthopedic Surgery, Akershus University Hospital, Lorenskog, Norway

Correspondence to Dr Per-Henrik Randsborg; Per-Henrik.Randsborg@ahus.no
Alexander Y Liebeskind (D) , ${ }^{1}$ Marc Nieuwenhuijse, ${ }^{2,3}$ Jensen $\mathrm{H}$ Hyde, ${ }^{4}$ Amanda C Chen, ${ }^{1}$ Suvekshya Aryal, ${ }^{1}$ Per-Henrik Randsborg (i) 5,6

\section{INTRODUCTION}

The prevalence of osteoarthritis doubled in the USA between 1999 and 2014, ${ }^{1}$ making the condition the single largest contributor to health-related costs. ${ }^{2}$ Consequently, over 1 million total joint arthroplasties (TJAs) are performed each year in the USA, and this number is expected to exceed 4 million by $2030 .{ }^{3}$

Rising healthcare costs related to low value care require quantification of efficacy and safety from the patient's perspective. ${ }^{4}$ Patient reported outcome measures (PROMs) are typically used to assess the patient orientated efficacy of joint replacements. PROMs include joint-specific and generic questionnairebased endpoints. Implant survival is also used as safety and performance metric.

Systematic reviews are at the top of the evidence pyramid. The quality of the aggregated evidence depends on the amount of analyzable data available for meta-analysis. The purpose of this commentary is not to provide a meta-analysis or systematic review of outcome after total hip and knee arthroplasties, but to demonstrate that the lack of

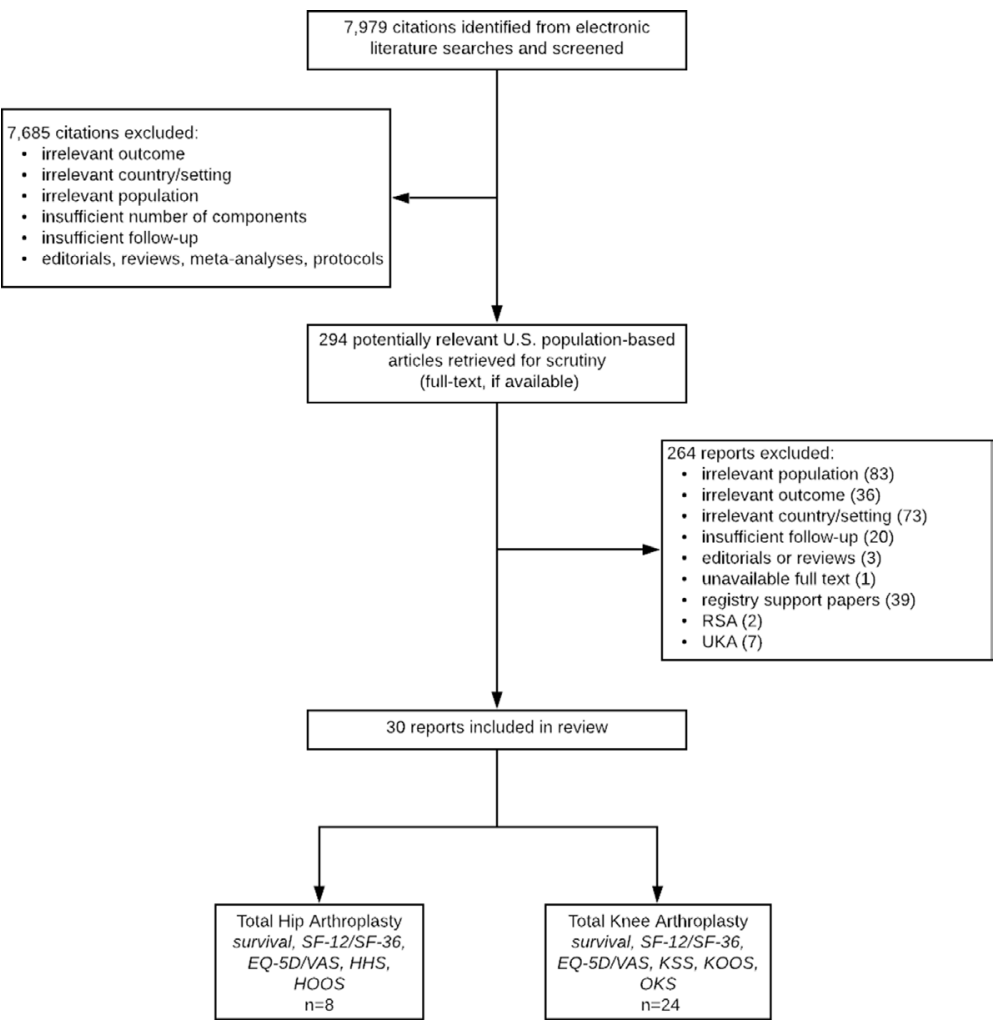

Figure 1 Preferred Reporting Items for Systematic Reviews and Meta-Analyses flowchart illustrating the process of evidence review and the number of studies included in the analysis (note: two studies citing both hip and knee patient reported outcome measures met inclusion criteria). EQ5D, EuroQol-5 Dimension; HHS, Harris Hip Score; HOOS, Hip Injury and Osteoarthritis Outcome Score; KOOS, Knee Injury and Osteoarthritis Outcome Score; KSS, Knee Society Score; OKS, Oxford Knee Score; RSA, Resurfacing Arthroplasty; SF, Short Form; UKA, Unicompartmental Knee Arthroplasty; VAS, Visual Analouge Scale. 
Table 1 Percentage of publications presenting compatible and analyzable endpoints extracted from 30 studies included in a systematic review of 7979 publications on total joint arthroplasty

\begin{tabular}{|c|c|c|c|c|c|c|}
\hline \multirow[b]{2}{*}{ Outcome measure } & \multicolumn{3}{|c|}{ Total hip arthroplasty studies $(n=8)$} & \multicolumn{3}{|c|}{ Total knee arthroplasty studies $(n=24)$} \\
\hline & Preoperation & 2 year & 5year & Preoperation & 2 year & 5year \\
\hline KOOS & - & - & - & $3(12.5 \%)$ & $3(12.5 \%)$ & $1(4.17 \%)$ \\
\hline Oxford Knee Score & - & - & - & $2(8.3 \%)$ & $2(8.3 \%)$ & $0(0 \%)$ \\
\hline HOOS & $2(25 \%)$ & $2(25 \%)$ & $0(0 \%)$ & - & - & - \\
\hline Oxford Hip Score & $0(0 \%)$ & $0(0 \%)$ & $0(0 \%)$ & - & - & - \\
\hline EuroQol-Index & $1(12.5 \%)$ & $1(12.5 \%)$ & $0(0 \%)$ & $2(8.3 \%)$ & $2(8.3 \%)$ & $0(0 \%)$ \\
\hline Short Form & $3(37.5 \%)$ & 3 (37.5\%) & $1(12.5 \%)$ & $10(41.7 \%)$ & $10(41.7 \%)$ & 3 (12.5\%) \\
\hline Survival rate & - & 7 (87.5\%) & $3(37.5 \%)$ & - & 12 (50.0\%) & $10(41.7 \%)$ \\
\hline
\end{tabular}

HOOS, Hip Injury and Osteoarthritis Outcome Score; KOOS, Knee Injury and Osteoarthritis Outcome Score.

harmonized data reporting makes aggregate knowledge synthesis near impossible despite thousands of available publications.

\section{MATERIALS AND METHODS}

We reviewed 7979 publications related to total knee arthroplasty (TKA) and total hip arthroplasty (THA). The study pool was drawn from PubMed, MEDLINE, Embase, EMCare, Web of Science and Cochrane Library. To ensure inclusion and exclusion criteria were satisfied, the literature sample was subjected to a multiround, paired peer-verified screening process (figure 1). Studies were included that met a 90\% osteoarthritis population diagnosis rate and with a US study population. Exclusion criteria included irrelevant population, country, or outcome, insufficient follow-up (less than 2-year survival rate, revision rate, or PROM data), insufficient sample size $(<100$ for randomised controlled trials or $<250$ for observational studies), or extraneous area of focus (Unicompartmental Knee Arthroplasty (UKA), resurfacing, etc). Editorials and reviews were excluded. Between rounds, studies were reassigned for assessment in order to limit potential bias and optimize data extraction. Data were extracted from the publications which passed the systematic review process. This primary data set was analyzed to assess data reporting related to extractable PROM endpoints and implant survival (figure 1).

\section{RESULTS}

Following title and abstract screening, 294 papers met initial inclusion criteria for full-text assessment, of which $30(10.2 \%)$ studies (2 including both hip and knee data) met final inclusion criteria. Survival rates were cited by $87.5 \%$ and $37.5 \%$ of THA studies and $50.0 \%$ and $41.7 \%$ of TKA studies at 2 and 5 years, respectively, which exceeded average reporting rates for joint-specific or generic PROMs (table 1). Given the potential for 8 THA and 24 TKA aggregated endpoints, total extractable data were markedly low.

\section{DISCUSSION}

We found two primary problems in our evidence assessment: (1) reporting of PROMs differs across publications and (2) endpoints are presented using incomparable parameters. These obstacles critically undermine consolidated analysis by reducing the number of analyzable endpoints per study.

Our results show that there is a dire need for standardization in the quantification and reporting of TJA outcome measures. The inability to compute aggregate data inhibits generation of surgical protocols and hinders device regulation, which is important for public health and policymaking. Publications that cannot be included in aggregate data analysis miss the opportunity to improve practice, the key goal of scientific publications. These findings corroborate past results: one recent review of four orthopedic journals identified over 40 different knee and hip specific PROM types. ${ }^{4}$ This multitude of outcome measures compromises between-study comparability and evidence synthesis for construction of performance benchmarks and clinical and regulatory guidelines.

Removing unnecessary obstacles to aggregated data analysis in publications related to joint replacement will lead to stronger evidence generation, subsequent improvement of TJA outcomes and reduction in scientific waste. We therefore call for publishers, stakeholders, and professional societies to harmonize data reporting in joint replacement with support from key regulators. It is essential that future PROM studies adopt standard reporting practices, minimum data guidelines, and PROM conversion crosswalks ${ }^{5}$ to prevent research waste.

Twitter Per-Henrik Randsborg @randsborg 
Contributors AYL, MN, JHH, ACC, SA, and P-HR contributed to inclusion and exclusion criteria, orthopedic study review, data extraction, and provided consultation on methodology. Authors AYL, MN, JHH, and P-HR were additionally responsible for analysis and manuscript writing and editing.

Funding This work was supported by the Food and Drug Administration, Center for Devices and Radiological Health, grant number U01FD006292.

Disclaimer Marc Nieuwenhuijse is an Editorial Board Member.

Competing interests None declared.

Patient consent for publication Not required.

Provenance and peer review Not commissioned; externally peer reviewed.

Open access This is an open access article distributed in accordance with the Creative Commons Attribution Non Commercial (CC BY-NC 4.0) license, which permits others to distribute, remix, adapt, build upon this work non-commercially, and license their derivative works on different terms, provided the original work is properly cited, appropriate credit is given, any changes made indicated, and the use is non-commercial. See: http://creativecommons.org/licenses/by-nc/4.0/.
ORCID iDs

Alexander Y Liebeskind http://orcid.org/0000-0002-2457-8662

Per-Henrik Randsborg http://orcid.org/0000-0002-7674-1572

\section{REFERENCES}

1 Park J, Mendy A, Vieira ER. Various types of arthritis in the United States: prevalence and age-related trends from 1999 to 2014. Am J Public Health 2018;108:256-8.

2 Hunter DJ, Schofield D, Callander E. The individual and socioeconomic impact of osteoarthritis. Nat Rev Rheumatol 2014;10:437-41.

3 Etkin CD, Springer BD. The American joint replacement Registry-the first 5 years. Arthroplast Today 2017;3:67-9.

4 Siljander MP, McQuivey KS, Fahs AM, et al. Current trends in patientreported outcome measures in total joint arthroplasty: a study of 4 major orthopaedic journals. J Arthroplasty 2018;33:3416-21.

5 Polascik BA, Hidaka C, Thompson MC, et al. Crosswalks between knee and hip arthroplasty short forms: HOOS/KOOS jr and Oxford. $J$ Bone Joint Surg Am 2020;102:983-90. 